\title{
Biochar Amendment Increases Resistance to Stem Lesions Caused by Phytophthora spp. in Tree Seedlings
}

\author{
Drew C. Zwart and Soo-Hyung Kim ${ }^{1}$ \\ Center for Urban Horticulture, School of Environmental and Forest \\ Sciences, College of the Environment, University of Washington, 3501 NE \\ 41st Street, Box 354115, Seattle, WA 98195
}

Additional index words. red oak, Quercus rubra, red maple, Acer rubrum, Phytophthora cinnamomi, Phytophthora cactorum, phosphorous acid

\begin{abstract}
Soil amendment with biochar is thought to confer multiple benefits to plants including induction of systemic resistance to plant pathogens. Pathogens in the genus Phytophthora cause damaging diseases of woody species throughout the world. The objective of this study was to test 1) whether biochar amendment induces resistance to canker causing Phytophthora pathogens; and 2) how this resistance is related to the amount of biochar amendment in two common landscape tree species: Quercus rubra (L.) and Acer rubrum (L.). Seedlings of $Q$. rubra and $A$. rubrum were planted in peatmoss-based potting mix uniformly amended with $0 \%, 5 \%, 10 \%$, or $20 \%$ biochar by volume. Plants in each treatment group were stem wound-inoculated with an isolate of Phytophthora cinnamomi Rands (host: Q. rubra) or P. cactorum (Leb. and Cohn) Schröeter (host: A. rubrum) using standard agar-plug inoculation procedures. Amendment of potting media with $5 \%$ biochar reduced horizontal expansion of lesions in both hosts, whereas the same treatment significantly reduced vertical expansion of lesions in $A$. rubrum $(P<0.05)$. In addition, $5 \%$ biochar resulted in a higher midday stem water potential in $Q$. rubra $(P=0.066)$ and significantly greater stem biomass in $A$. rubrum compared with inoculated control plants ( $0 \%$ biochar, $P<0.05$ ). Our results suggest that biochar amendment has the potential to alleviate disease progression and physiological stress caused by Phytophthora canker pathogens and there is likely an optimal level of biochar incorporation into the root media beyond which the effects may be less pronounced.
\end{abstract}

Plant diseases caused by organisms in the genus Phytophthora negatively impact nursery stock, field crops, tree crops, and forest systems (Erwin and Ribeiro, 1996; Hansen et al., 2008). Phytophthora diseases are also widespread and damaging to woody plants that are commonly found in managed landscapes. In trees, Phytophthora pathogens can cause fine root disease, root collar or crown rots, and trunk or stem lesions that are often referred to as "bleeding cankers" (Erwin and Ribeiro, 1996). Physiologically, stem canker-causing Phytophthora species (e.g., P. cinnamomi and $P$. cactorum) are known to kill phloem, leading to plant death through girdling, and also to colonize and block xylem, leading to altered plant water relations (Brown and Brasier, 2007).

Chemical and non-chemical management options are increasingly being sought to preserve valuable infected specimen trees and

Received for publication 27 June 2012. Accepted for publication 13 Oct. 2012.

This work was funded in part by The Bartlett Tree Expert Co.

We thank Ashura Takanohara for his assistance with this work.

The funders had no role in study design, data collection and analysis, decision to publish, or manuscript preparation.

${ }^{1}$ To whom reprint requests should be addressed; e-mail soohkim@uw.edu. biochar or may be the result of biochar-related alterations in the soil microbial community (Elad et al., 2011; Kolton et al., 2011; Warnock et al., 2007). If SIR was the cause of the observed decrease in disease severity, similar results may be possible in defense against Phytophthora pathogens. The potential for biochar incorporation as a disease management option has only recently been suggested and research to date is limited (Elad et al., 2011; Lehmann et al., 2011).

The objective of the present study was to determine if biochar amendment of a soilless potting media can reduce the development and impact of stem lesions caused by Phytophthora spp. on common nursery and landscape hosts and to determine if an optimal rate of biochar amendment exists beyond which benefits are reduced. By testing an aboveground disease and providing all plants with ample nutrients and moisture, any reduction in disease severity resulting from biochar incorporation can reasonably be attributed to an increased systemic resistance in the plant rather than a direct effect of biochar on the pathogen. Separate experiments on two host-pathogen systems were conducted to test the hypothesis of induced resistance and to determine the potential effectiveness for this soil amendment treatment on two combinations of plant host and Phytophthora pathogen.

\section{Materials and Methods}

Treatments. Treatments consisted of varying levels of biochar amendment by volume to potting mix $(5 \%, 10 \%, 20 \%$, or $0 \%$ control $)$ in inoculated plants in both experiments, a noninoculated control (no biochar amendment) in the maple experiment and a chemically treated and inoculated treatment (no biochar amendment) in the maple experiment. In the non-amended treatments, inoculated plants growing in $0 \%$ biochar amended potting mix are referred to as $0 \%+$, whereas non-inoculated plants growing in $0 \%$ biochar are referred to as $0 \%-$. The chemically treated seedlings were planted in potting mix without biochar and each pot was drenched with 1 pint $(473 \mathrm{~mL})$ Agrifos $^{\circledR}$ (mono- and dipotassium salts of phosphorous acid; Liquid Fertiliser Pty. Ltd., Queensland, Australia) $6 \mathrm{~d}$ before inoculation according to labeled rates for ornamental applications (0.3549 L per 378.54 L of water).

The biochar used in this experiment was produced from pine parent material (Pinus taeda, P. palustris, $P$. echinata, $P$. elliotti), which was pyrolyzed for $1 \mathrm{~h}$ between temperatures of 550 and $600{ }^{\circ} \mathrm{C}$ in a pyro-torrefaction style kiln. The biochar was ground to create particle sizes between four and six mesh. The biochar contained (\% dry weight): $1.0 \%$ mobile carbon $(\mathrm{C})$, $63.1 \%$ resident $\mathrm{C}, 0.1 \%$ mobile nitrogen $(\mathrm{N})$, $0.3 \%$ resident $\mathrm{N}, 17 \%$ mobile hydrogen-oxygen (H-O), 6.8\% resident $\mathrm{H}-\mathrm{O}, 8.6 \%$ soluble ash, $3.7 \%$ non-soluble ash (analyzed July 2011 by Control Laboratories Inc., Soil Control Laboratory, Watsonville, CA). The biochar was obtained from New Earth Renewable Energy, a commercial producer that is no longer in operation. 
Plant materials. Red maple (Acer rubrum) seedlings used in this experiment were seedgrown two-year-old plants (15- to 30-cm bareroot seedlings) obtained from Lawyer Nursery (Olympia, WA) and planted on 15 June 2011 at the University of Washington Center for Urban Horticulture, Seattle, WA. Root systems were washed, cut to a uniform length of $15 \mathrm{~cm}$, and planted in 2.54-L tree pots containing Sunshine Professional Growing Mix \#2 (75\% to 85\% Canadian sphagnum peatmoss, horticulturalgrade perlite, dolomitic limestone; Sun Gro Horticulture, Canada Ltd.) amended with $0 \%$, $5 \%, 10 \%$, or $20 \%$ biochar by volume. Maple seedlings were inoculated on 18 July and grown under greenhouse conditions with average temperature and average relative humidity maintained at $20.7^{\circ} \mathrm{C}$ and $53.09 \%$, respectively, until harvest $108 \mathrm{~d}$ post-inoculation. Maple treatment groups each consisted of 20 seedlings, randomly arranged on adjacent greenhouse tables.

Red oak (Quercus rubra) seedlings used in this experiment were seed-grown two-year-old plants (small plugs) obtained from Heritage Seedlings (Salem, OR) and planted on 5 Mar. 2011 in Seattle, WA. At planting, root systems were washed, and seedlings were planted in Sunshine Professional Growing Mix \#2 amended with $0 \%, 5 \%, 10 \%$, or $20 \%$ biochar by volume in $455-\mathrm{mL}$ pots $(10.36 \mathrm{~cm}$ top, $6.95 \mathrm{~cm}$ bottom, $8.71 \mathrm{~cm}$ depth; T.O. Plastics, Minneapolis, MN). All oak seedlings were maintained under greenhouse conditions for one month, moved outdoors, inoculated on 14 June, and grown under ambient weather conditions (Seattle, WA) for the duration of the experiment $(65 \mathrm{~d})$. There was no noninoculated control or chemical treatment in the oak experiment. During the experiment, average daily temperature ranged from 7.5 to $18.78^{\circ} \mathrm{C}$ ( single day high $30.55^{\circ} \mathrm{C}$, single day low $0.556^{\circ} \mathrm{C}$ ) with $25.22 \mathrm{~cm}$ of rain over the duration, over $90 \%$ of which occurred April through June (National Weather Service Data, Seattle-Tacoma International Airport station). Treatment groups each consisted of 14 or 15 randomly arranged seedlings.

All plants were monitored daily, watered by hand as needed to maintain near-constant field capacity conditions, and fertilized weekly with Hoagland's \#2 nutrient solution mixed at half strength as described in Kinmonth-Schultz and Kim (2011).

Pathogens. The isolates of $P$. cactorum and $P$. cinnamomi used in this experiment were isolated through direct plating of phloem tissue from the margin of necrotic lesions that were associated with symptoms of "bleeding cankers" typical of Phytophthora spp. infections on a red maple (Acer rubrum, Indian Land, SC) and shingle oak (Quercus imbricaria, Washington Park Arboretum, Seattle, WA), respectively. The isolates were identified by morphology, and identification of the $P$. cinnamomi isolate was confirmed at the University of Washington DNA Sequencing Facility based on the ITS- 1 and ITS-2 rRNA subunits using polymerase chain reaction techniques.

Inoculation. A stem wound technique was used to introduce the pathogen into seedlings of both plant species in the inoculated treatments.
A 5-mm diameter disc of bark and phloem was removed from the lower stem using a sterile cork borer and razor blade. Immediately after wound creation, a 5-mm diameter agar plug was taken from the margin of an actively growing colony of the pathogen and placed on the wound with the upper surface facing inward. A sterile agar plug was placed on the wound of noninoculated control treatments. All inoculation sites were immediately wrapped with moist sterile gauze followed by a layer of parafilm to maintain adequate moisture for infection and then covered with a layer of aluminum foil to exclude light.

Cultures of both pathogens were isolated and maintained in the dark on a clarified V8 juice agar selective for the culture of oomycete organisms (Jeffers and Martin, 1986).

Resistance assessment. Lesion size, stem water potential (oak only), and biomass were assessed at harvest, which took place $108 \mathrm{~d}$ after inoculation in the maple experiment and $65 \mathrm{~d}$ after inoculation in the oak experiment.

Vertical and horizontal advance of the pathogen, as evidenced by expansion of the necrotic lesion, was measured at the conclusion of the experiment. Lesion measurements were made at the edge of discolored, intact bark tissue. Vertical expansion was recorded as total length of the necrotic region, and horizontal expansion was recorded as the percentage of stem circumference girdled by the necroses. Removal of bark and examination of necrotic phloem tissue confirmed that the margin of discolored bark was indicative of the margin of the underlying necrotic lesion originating from the original inoculation point. After harvest, five plants from each treatment group were assessed to confirm pathogen colonization. Tissue from the margin of the necrosis was placed on PARP-V8 agar (Jeffers and Martin, 1986) and colony identity was verified morphologically.

At the conclusion of the trial after lesion measurements and reisolation, all seedlings were dried at $65{ }^{\circ} \mathrm{C}$ for at least $72 \mathrm{~h}$. Root and stem portions were separated and weighed. Leaf weight was not included because senescence and dropping of leaves during the course of the experiment occurred but were not recorded.

Stem water potential. In the oak experiment, midday stem water potential was determined at the conclusion of the experiment (18 Aug., 2011, 1300 to 1430) to assess the effects on plant water relations caused by colonization of xylem by the pathogen. A Scholander-type pressure chamber was used for this purpose (PMS Instrument Company, Albany, OR). The terminal 10 to $15 \mathrm{~cm}$ of each seedling was cut with a sharp razor blade and water potential measurements were made immediately. After measurements, the plant portion used in this analysis was included in the biomass measurements.

Statistical analysis. All statistical analyses were conducted using SigmaPlot 12.0 for windows statistical software (Systat Software Inc., San Jose, CA). The Type I error rate $(\alpha)$ was set at 0.05 for all treatment comparisons. Lesion size, biomass, and stem water potential were analyzed by one-way analysis of variance (ANOVA) with soil treatment (biochar amendment or chemical) as the main factor. When data failed the Shapiro-Wilk test for normality, treatment group means were compared using the Kruskal-Wallis ANOVA on ranks with soil treatment as the main factor. Means of treatment groups were compared using the Student-Newman-Keuls method in the case of equal sample sizes (maple) and using Dunn's method for unequal sample sizes (oak). Each treatment group was comprised of 20 seedlings in the maple experiment and 14 or 15 seedlings in the oak experiment.

\section{Results}

Attempts to reisolate Phytophthora cactorum and $P$. cinnamomi from margins of necrotic lesions were successful in all cases in which necrosis was evident. $P$. cactorum was not isolated from any non-inoculated plants. $P$. cactorum was isolated from chemically treated and inoculated plants when necrosis was evident (nine of 20 plants) but was not isolated from plants where no necrosis had developed. In the following sections, treatment groups are identified by the level of biochar amendment or as a chemical treatment (Chem). All biochar-amended plants and all chemically treated plants were inoculated.

\section{Maple experiment}

Lesion expansion. Data for vertical and horizontal expansion of necrotic lesions in the maple experiment failed the Shapiro-Wilk test for normality; therefore, treatment group means were compared using the Kruskal-Wallis oneway ANOVA on ranks. Treatment had a significant effect on lesion expansion; differences in means among treatment groups for both vertical and horizontal expansion were greater than would be expected by chance $(P<0.001)$. The Student-Newman-Keuls method was used for multiple comparisons to isolate differences between treatment groups $(P \leq 0.05)$. No necrotic lesions developed on non-inoculated plants $(0 \%-)$ and callus tissue had overgrown all wound sites (data not shown). Compared with the inoculated plants with no biochar amendment $(0 \%+)$, incorporation of $5 \%$ biochar significantly reduced vertical lesion expansion and the percentage of the stem circumference that was girdled by necrosis (Fig. 1). Amendment with 10\% biochar significantly reduced horizontal expansion of lesions compared with inoculated control plants, whereas amendment with $20 \%$ biochar increased horizontal expansion of lesions compared with inoculated control (Fig. 1A). Amendment of potting mix with $10 \%$ or $20 \%$ biochar did not significantly affect lesion vertical expansion compared with $0 \%+$ (Fig. 1B). Mean lesion expansion in chemically treated plants was significantly reduced compared with all other inoculated treatment, both vertically and horizontally, although some necrosis did develop on nine of 20 plants (Fig. 1), causing significant differences in mean lesion expansion compared with the non-inoculated control in which no lesions developed (not shown). 
Biomass production. Final dry biomass data in the maple experiment were normally distributed (Shapiro-Wilk, $P=0.538$ ) and treatment groups were equal in variance $(P=$ 0.328 ). Analysis of variance indicated a significant effect of treatment on stem, root, and total dry biomass $(P<0.001)$. Non-inoculated plants $(0 \%-)$ produced significantly more total biomass than any inoculated treatment. Inoculated plants that were chemically treated (Chem) produced significantly more total mean biomass than $0 \%+, 10 \%$, and $20 \%$ plants, but total mean biomass of chemically treated plants was not significantly different from the inoculated plants growing in 5\% biochar amendment (Fig. 2). Amendment with 5\% biochar significantly increased total mean biomass production compared with $10 \%$ and $20 \%$ treatments, but not compared with $0 \%+$.

When taken alone, biomass of stems revealed greater differences among treatments. Variability in root weights was greater than in stem weights, and the growth of all root systems had been altered by contact with the pot edges by the end of the experiment. For stem biomass, non-inoculated plants $(0 \%-)$ produced significantly more biomass than any inoculated treatment group. Inoculated plants that were chemically treated produced less stem biomass than the $0 \%$ - treatment but produced significantly more than any other inoculated treatment. Compared with the inoculated control $(0 \%+)$, amendment of potting mix with $5 \%$ biochar significantly increased stem biomass. Mean stem biomass of plants receiving the $10 \%$ or $20 \%$ treatments was not significantly different from each other, but both treatment groups produced significantly less mean stem biomass than the other treatments (Fig. 2).

\section{Oak experiment}

Lesion expansion. In the oak experiment, data for both vertical and horizontal lesion expansion failed the Shapiro-Wilk test for normality; therefore, means were compared using the Kruskal-Wallis ANOVA on ranks with soil

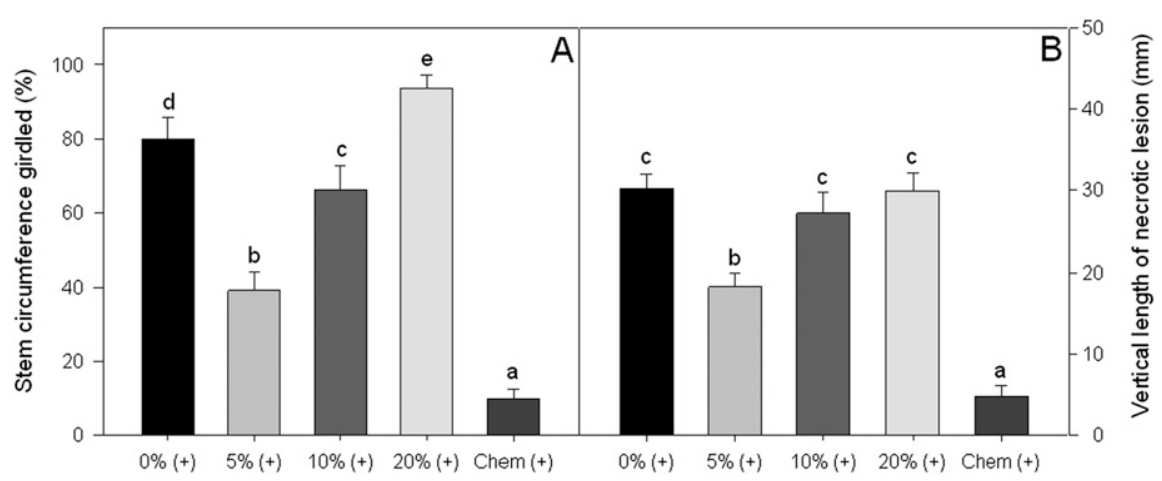

Fig. 1. Mean horizontal (A, \% circumference girdled) and vertical (B, mm) expansion of necrotic lesion caused by $P$. cactorum on $A$. rubrum seedlings $(\mathrm{n}=20)$. Treatment names include percent biochar incorporation and inoculation status. No lesions formed on non-inoculated, non-amended control seedlings (data not shown). Data were analyzed by one-way analysis of variance with biochar amendment as the main factor and there was a significant treatment effect $(P<0.001)$. Means without a letter in common are significantly different for that measurement (Student-Newman-Keuls Method for multiple comparisons, $P \leq 0.05)$. Bars are $1 \mathrm{SE}$.

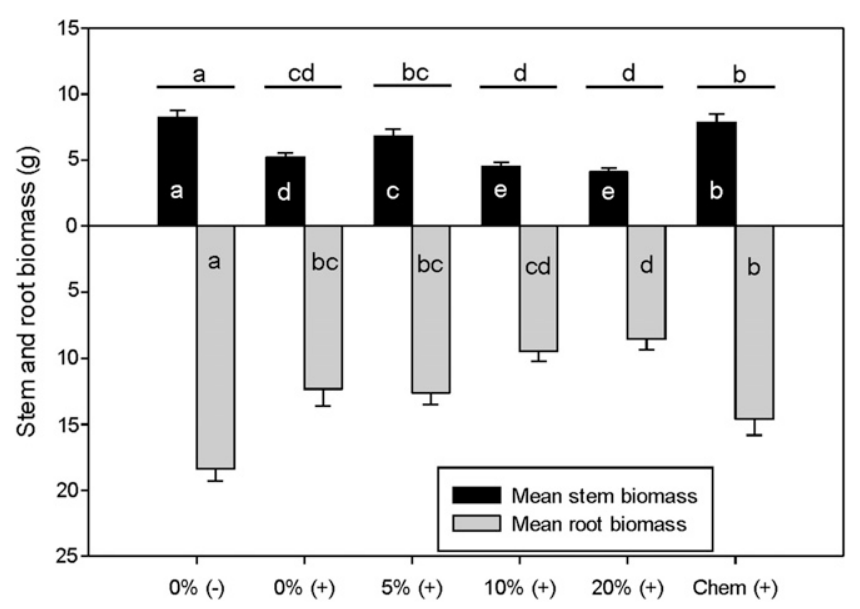

Fig. 2. Mean stem (above axis) and root (below axis) biomass of $A$. rubrum seedlings after soil treatment (control, \% biochar, chemical) and $108 \mathrm{~d}$ post-inoculation ( + or - ) with $P$. cactorum. Means that do not share a common letter within the plot are significantly different for that parameter, and letters above plots indicate differences in total biomass (Student-Newman-Keuls Method for multiple comparisons, $P \leq 0.05)$. Bars are $1 \mathrm{SE}$. treatment as the main factor. No significant difference was found between treatments group means for vertical lesion expansion $(P=0.311$; Table 1); however, mean values for this parameter in oak followed the same general trends as in the maple experiment. Also, when compared individually with the control, amendment with 5\% biochar showed a strong trend toward reduction of lesion vertical expansion ( $t$ test, $P=0.094$ ). Significant differences did exist between treatments for horizontal lesion expansion $(P=0.002)$ in the oak experiment, and multiple comparisons were made using Dunn's method as a result of the unequal sample sizes resulting from disruption by wildlife, which involved birds removing labels or whole plants from pots. Incorporation of 5\% biochar in the oak experiment significantly reduced horizontal expansion of lesions compared with all other treatments $(P \leq 0.05)$. No significant differences existed in horizontal lesion expansion among the $0 \%+, 10 \%$, or $20 \%$ treatments.

Dry biomass production. In the oak experiment, neither total biomass nor aboveground biomass data were normally distributed and were therefore compared using the KruskalWallis ANOVA on ranks. No significant differences existed between treatment group means for total biomass $(P=0.611)$ or for mean stem biomass $(P=0.602)$.

Midday stem water potential. In the oak experiment, data for midday stem water potential were not normally distributed $(P<0.05$, Shapiro-Wilk test); means from each treatment group were compared using the KruskalWallis ANOVA on ranks. Differences between treatment groups were marginally significant $(P=0.066)$ based on this test. Five percent biochar amendment resulted in the least negative mean value for stem water potential $(-0.457$ $\mathrm{MPa}$ ) followed by the $10 \%$ treatment and the $0 \%+$ treatment, which were nearly the same $(-0.527 \mathrm{MPa}$ and $-0.528 \mathrm{MPa}$, respectively). The mean stem water potential in the $20 \%$ treatment $(-0.561 \mathrm{MPa})$ was the most negative (Table 1).

\section{Discussion}

Overall, amendment of potting mix with $5 \%$ biochar resulted in reduced lesion expansion and greater stem biomass when compared with plants growing in media that was not amended or amended with $10 \%$ or $20 \%$ biochar $(\mathrm{v} / \mathrm{v})$. Biologically, the horizontal expansion of lesions, leading to the complete girdling of phloem in stems, probably has a greater effect on overall plant health than vertical expansion, which would not completely girdle the stem, and this parameter showed some of the greatest differences between treatments. Although non-significant at $P \leq 0.05$, the trends seen in stem water potential data from the oak experiment are also of interest. Visual inspection of discolored tissue indicated that the pathogen had colonized xylem tissue in addition to causing phloem necrosis, and the water potential data support this observation because the smallest lesion sizes and least negative water potentials 
Table 1. Expansion of necrotic lesion, midday stem water potential, and stem biomass of Quercus rubra seedlings at $65 \mathrm{~d}$ post-inoculation with Phytophthora cinnamomi. ${ }^{\mathrm{z}}$

\begin{tabular}{lcccccc}
\hline & \multicolumn{2}{c}{ Expansion of necroses } & & \multicolumn{2}{c}{ Midday stem water potential } & \\
\cline { 2 - 3 } Treatment & Percent girdled & Vertical length $(\mathrm{mm})$ & & MPa & $t$ test vs. control & Biomass $(\mathrm{g})$ \\
\hline $0 \%$ & $82.0 \%(5.34) \mathrm{b}^{\mathrm{y}}$ & $49.8(7.82)$ & & $-0.528(0.03)$ & NA & $13.93(0.81)$ \\
$5 \%$ & $57.4 \%(4.55) \mathrm{a}$ & $33.0(5.84)$ & & $-0.457(0.02)$ & $P=0.110$ & $12.72(0.66)$ \\
$10 \%$ & $85.9 \%(5.14) \mathrm{b}$ & $46.5(8.92)$ & & $-0.527(0.03)$ & $P=0.942$ & $12.95(0.88)$ \\
$20 \%$ & $85.3 \%(5.69) \mathrm{b}$ & $51.1(7.71)$ & & $-0.561(0.03)$ & $P=0.468$ & $12.71(0.69)$ \\
F-test & $P=0.002$ & $P=0.311$ & $P=0.066$ & & $P=0.611$ \\
\hline
\end{tabular}

${ }^{\mathrm{z}}$ Values in parentheses are $1 \mathrm{SE}$. When one-way analysis of variance showed significant differences between treatments, Dunn's method was used for multiple comparisons.

${ }^{\mathrm{y}}$ Girdling percentage means without a common letter are significantly different $(P \leq 0.05)$.

$\mathrm{NA}=$ not applicable.

both occurred in the $5 \%$ treatment, indicating a potential physical blockage hindering the movement of water. The degree of potential xylem vessel blockage in this study appears to be similar to or less than the xylem blockage resulting from other physical damages such as stem bending (Kim et al., 2004). Previous studies have also shown xylem colonization and blockage in woody stems caused by various Phytophthora pathogens (Brown and Brasier, 2007; Parke and Lewis, 2007).

Amendment of potting media with 5\% biochar did not prevent lesion development or increase biomass as well as treatment with salts of phosphorous acid, a material known to induce resistance against Phytophthora spp. (Daniel and Guest, 2006; Daniel et al., 2005; Garbelotto et al., 2009; Jackson et al., 2000; Weiland et al., 2009). However, based on this study and previous studies involving other pathogen/host combinations (Elad et al., 2010; Harel et al., 2012), it appears that amendment of rooting media with $5 \%$ biochar has the potential to induce some level of resistance against a wide range of pathogens. The experiment using red oak (Quercus rubra) and Phytophthora cinnamomi resulted in comparable, although often non-significant, trends compared with the experiment using red maple (Acer rubrum). In the oak experiment, disruptions of the plots by wildlife led to a loss of $20 \%$ to $25 \%$ of treatment replicates. Although many of the parameters under investigation followed similar trends between the maple and oak experiments, the reduction of statistical power in the oak experiment resulting from loss of plants reduced the potential significance of differences in means among treatment groups in that experiment. Despite the lack of significance for some parameters, the similar results from each experiment suggest promising potential for this soil amendment to benefit other pathosystems involving woody plants and pathogens in the genus Phytophthora.

There are many mechanisms by which biochar amendment may lead to increased resistance to plant disease, including increase in overall plant vigor, increased nutrient availability, alteration of soil $\mathrm{pH}$, altered soil moisture, increase in mycorrhizal associations or other beneficial rhizosphere microorganisms, and changes in soil physical properties (Glaser and Zech, 2002; Ishii and Kadoya, 1994; Kolton et al., 2011; Lehmann et al., 2011; Novak et al., 2009; Warnock et al., 2007). Effects of biochar amendment on soil $\mathrm{pH}$, soil drainage, soil physical properties, and microbial communities may directly impact Phytophthora spp. in soil. However, the experiments described here were designed to eliminate any direct effects on the pathogen caused by soil physical, chemical, or microbial properties through inoculation of above-soil stem tissue. Effects of soil physical or chemical properties on resistance were controlled for through provision of plants with ample moisture and nutrients in horticultural growth media Based on this design, the results here are indicative of a systemic response and are in agreement with previous research that showed a reduction in damage caused by foliar plant diseases in multiple host plants after incorporation of biochar into various media (Elad et al., 2010; Harel et al., 2012). In those pioneering studies, the authors concluded that the induced resistance may have been the result of an increase in beneficial soil microorganisms, elicitation of plant defense responses after stress to the plant caused by low-level phytotoxic compounds in the biochar material, or chemical elicitors.

Although the present study does not explicitly support one potential mechanism or another, based on the apparent dose-dependency of the results, induction of defense through low-level stress appears to be a likely possibility. Although amendment of media with 5\% biochar did reduce lesion size and increase biomass compared with the untreated control group, higher rates were not beneficial and in some cases appeared to become detrimental. This would appear to support the concept of hormesis, i.e., that low levels of phytotoxic compounds can stimulate growth or defense in plants (Graber et al., 2010; Prithiviraj et al., 2007). Further studies that investigate other key physiological aspects including carbon assimilation, production of defense compounds, photosynthetic efficiency, and foliar starch content will be needed to unveil the mechanisms responsible for the reduction of lesion development and increase in biomass production. A decrease in stomatal conductance, carbon assimilation, and photochemical efficiency after infection with canker-causing Phytophthora species has been attributed to several factors in previous studies. Impaired water movement in xylem and subsequent drought stress (Luque et al., 1999), pathogenderived chemical elicitors (Fleischmann et al., 2005; Manter et al., 2007), or a feedback inhibition caused by starch accumulation in foliage as a result of dead or non-functional phloem (Clemenz et al., 2008) have all been implicated as the main causes for the effects of inoculation on carbon assimilation. Although we have shown a reduction in disease progression with biochar amendment, our data do not explicitly support or negate any of these potential mechanisms.

Here we have shown that amendment of potting media with $5 \%$ biochar can reduce the expansion of necrotic lesions caused by Phytophthora spp. in seedlings of two common landscape tree species. In addition, we have shown an apparent dose-dependency of the benefits of biochar amendment, because amendment of potting mix with $5 \%$ biochar limited disease development but increased levels $(10 \%$ and $20 \%)$ caused no change or had deleterious effects on the parameters under investigation.

\section{Literature Cited}

Agostini, J.P., P.M. Bushong, and L.W. Timmer. 2003. Greenhouse evaluation of products that induce host resistance for control of scab, melanose, and Alternaria brown spot of Citrus. Plant Dis. 87:69-74.

Brown, A.V. and C.M. Brasier. 2007. Colonization of tree xylem by Phytophthora ramorum, $P$. kernoviae, and other Phytophthora species. Plant Pathol. 56:227-241.

Clemenz, C., F. Fleischmann, K.-H. Haberle, R. Matyssek, and W. Oswald. 2008. Photosynthetic and leaf water potential responses of Alnus glutinosa saplings to stem-base inoculation with Phytophthora alni subsp. alni. Tree Physiol. 28:1703-1711

Daniel, R. and D. Guest. 2006. Defence responses induced by potassium phosphonate in Phytophthora palmivora-challenged Arabidopsis thaliana. Physiol. Mol. Plant Pathol. 67:194-201.

Daniel, R., B.A. Wilson, and D.M. Cahill. 2005. Potassium phosphonate alters the defence response of Xanthorrhea australis following infection by Phytophthora cinnamomi. Australas. Plant Pathol. 34:541-548.

Elad, Y., E. Cytryn, Y.M. Harel, B. Lew, and E.R. Graber. 2011. The biochar effect: Plant resistance to biotic stresses. Phytopathol. Mediterr. 50:335-349.

Elad, Y., D.R. David, Y.M. Harel, M. Borenshtein, H.B. Kalifa, A. Silber, and E.R. Graber. 2010. Induction of systemic resistance in plants by biochar, a soil applied carbon sequestering agent. Phytopathology 100:913-921.

Elliott, M. and R.L. Edmonds. 2008. Injected treatments for management of Madrone canker. Arboriculture and Urban Forestry 34:110-115.

Erwin, D.C. and O.K. Ribeiro. 1996. Phytophthora diseases worldwide. APS Press, St. Paul, MN.

Fleischmann, F., J. Koehl, R. Portz, A.B. Beltrame, and W. Oswald. 2005. Physiological changes of Fagus sylvatica seedlings infected with Phytophthora citricola and the contribution of elicitin 'citricolin' to pathogenisis. Plant Biol. 7:650-658

Garbelotto, M., T.Y. Harnik, and D.J. Schmidt. 2009. Efficacy of phosphonic acid, metalaxyl$\mathrm{M}$ and copper hydroxide against Phytophthora ramorum in vitro and in planta. Plant Pathol. 58:111-119.

Glaser, B. and J.L.W. Zech. 2002. Ameliorating physical and chemical properties of highly 
weathered soils in the tropics with charcoal - A review. Biol. Fertil. Soils 35:219-230.

Graber, E.R., Y.M. Harel, M. Kolton, E. Cytryn, A. Silber, D.R. David, L. Tsechansky, M. Borenshtein, and Y. Elad. 2010. Biochar impact on development and productivity of pepper and tomato grown in fertigated soilless media. Plant Soil 337:481-496.

Hansen, E.M., P.B. Hamm, and L.F. Roth. 2008. Alien forest pathogens: Phytophthora species are changing world forests. Boreal Environment Research 13:33-41.

Harel, Y., Y. Elad, D.R. David, M. Borenshtein, R. Shulchani, B. Lew, and E.R. Graber. 2012. Biochar mediates systemic response of strawberry to foliar fungal pathogens. Plant Soil 1-13 (online).

Ishii, T. and K. Kadoya. 1994. Effects of charcoal as a soil conditioner on Citrus growth and vesicular-arbuscular mycorrhizal development. J. Jpn. Soc. Hort. Sci. 63:529-535.

Jackson, T.J., T. Burgess, I. Colquhoun, and G.E.S. Hardy. 2000. Action of the fungicide phosphite on Eucalyptus marginata inoculated with Phytophthora cinnamomi. Plant Pathol. 49: 147-154.

Jeffers, S.N. and S.B. Martin. 1986. Comparison of two media selective for Phytophthora and Pythium species. Plant Dis. 70:1038-1043.
Kim, S.-H., K.A. Shackel, and J.H. Lieth. 2004 Bending alters water balance and reduces photosynthesis of rose shoots. J. Amer. Soc. Hort. Sci. 129:896-901.

Kinmonth-Schultz, H. and S.H. Kim. 2011. Carbon gain, allocation, and storage in rhizomes in response to elevated atmospheric carbon dioxide and nutrient supply in a perennial C3 grass, Phalaris arundinacea. Funct. Plant Biol. 38:797-807.

Kolton, M., Y. Harel, P. Zohar, E.R. Graber, Y. Elad, and E. Cytryn. 2011. Impact of biochar application to soil on the root-associated bacterial community structure of fully developed greenhouse pepper plants. Appl. Environ. Microbiol. 77:4924-4930.

Lehmann, J., M.C. Rillig, J. Thies, C.A. Masiello, W.C. Hockaday, and D. Crowley. 2011. Biochar effects on soil biota-A review. Soil Biol. Biochem. 43:1812-1836.

Luque, J., M. Cohen, R. Save, C. Biel, and I.F. Alvarez. 1999. Effects of three fungal pathogens on water relations, chlorophyll fluorescence, and growth. Ann. For. Sci. 56:19-26.

Manter, D.K., R.G. Kelsey, and J.J. Karchesy. 2007. Photosynthetic declines in Phytophthora ramorum-infected plants develop prior to water stress and in response to exogenous application of elicitins. Phytopathology 97:850-856.
Novak, J.M., W.J. Busscher, D.L. Laird, M. Ahmedna, D.W. Watts, and M.A.S. Niandou. 2009. Impact of biochar amendment on fertility of a southeastern coastal plain soil. Soil Sci. 174:105-112.

Parke, J.L. and C. Lewis. 2007. Root and stem infection of Rhododendron from potting medium infested with Phytophthora ramorum. Plant Dis. 91:1265-1270.

Percival, G. and K. Noviss. 2010. Evaluation of potassium phosphite and myclobutanil combinations for pear scab (Venturia pirina) suppression. Arboriculture and Urban Forestry 36: 86-92.

Prithiviraj, B., L.G. Perry, D.V. Badri, and J.M. Vivanco. 2007. Chemical facilitation and induced pathogen resistance mediated by a root-secreted phytotoxin. New Phytol. 173: 852-860.

Warnock, D.D., J. Lehmann, T.W. Kuyper, and M.C. Rillig. 2007. Mycorrhizal responses to biochar in soil-Concepts and mechanisms. Plant Soil 300:9-20.

Weiland, J.E., A.H. Nelson, and G.W. Hudler. 2009. Effects of mefenoxam, phosphonate, and paclobutrazol on in vitro characteristics of Phytophthora cactorum and P. citricola and on canker size of European beech. Plant Dis. 93:741-746. 